\title{
Glycomimetic Based Approach toward Selective Carbonic Anhydrase Inhibitors
}

Debora Pratesi, ${ }^{\dagger}$ Camilla Matassini,${ }^{\dagger}$ Andrea Goti, ${ }^{\dagger}{ }^{\dagger}$ Andrea Angeli, ${ }^{\#}$ Fabrizio Carta, ${ }^{\#}$ Claudiu T. Supuran, ${ }^{* \#}$ Rolando Spanevello ${ }^{\&}$ and Francesca Cardona ${ }^{\dagger *}$

$\dagger$ Dipartimento di Chimica 'Ugo Schiff', Università di Firenze, via della Lastruccia n. 3-13, Sesto Fiorentino (FI), Italy; francesca.cardona@unifi.it

$\$$ Associated with Consorzio Interuniversitario Nazionale di ricerca in Metodologie e Processi Innovativi di Sintesi (CINMPIS), 70100 Bari, Italy

\#Università degli Studi di Firenze, Dipartimento Neurofarba, Sezione di Scienze Farmaceutiche e Nutraceutiche, Via U. Schiff 6, 50019, Sesto Fiorentino, Florence, Italy; claudiu.supuran@unifi.it

\&Instituto de Química Rosario, Facultad de Ciencias Bioquímica y Farmacéuticas, Universidad Nacional de Rosario, CONICET, Suipacha 531, S2002LRK Rosario, Argentina

\section{SUPPORTING INFORMATION}




\section{Table of contents}

$\begin{array}{ll}\text { General methods } & \text { S3 }\end{array}$

$\begin{array}{ll}\text { Synthesis and characterization of compound } \mathbf{8} & \text { S4 }\end{array}$

$\begin{array}{ll}\text { Synthesis and characterization of compound } 4 & \text { S5 }\end{array}$

${ }^{1} \mathrm{HNMR}$ and ${ }^{13} \mathrm{CNMR}$ spectra of $4 \quad$ S6

$\begin{array}{ll}\text { Synthesis and characterization of compound } \mathbf{2} & \text { S7 }\end{array}$

${ }^{1} \mathrm{HNMR}$ and ${ }^{13} \mathrm{CNMR}$ spectrum of spectra of $\mathbf{2} \quad$ S8

$\begin{array}{ll}\text { Synthesis and characterization of compound } \mathbf{1 0} & \text { S9 }\end{array}$

$\begin{array}{ll}{ }^{1} \mathrm{HNMR} \text { and }{ }^{13} \mathrm{CNMR} \text { spectra of } \mathbf{1 0} & \text { S10 }\end{array}$

$\begin{array}{ll}\text { Structural study on the 1,3-dipolar cycloadduct } \mathbf{1 0} & \text { S11 }\end{array}$

$\begin{array}{ll}\text { Synthesis and characterization of compound } \mathbf{1 1} & \text { S12 }\end{array}$

${ }^{1}$ HNMR and ${ }^{13}$ CNMR spectra of $\mathbf{1 1} \quad$ S13

$\begin{array}{ll}\text { Synthesis and characterization of compound } \mathbf{1 2} & \text { S14 }\end{array}$

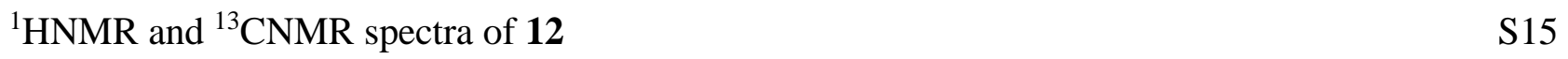

$\begin{array}{ll}\text { Synthesis and characterization of compounds } 7 \text { and } \mathbf{3} & \text { S16 }\end{array}$

$\begin{array}{ll}{ }^{1} \text { HNMR spectrum of compound } 3 & \text { S17 }\end{array}$

$\begin{array}{ll}{ }^{13} \mathrm{CNMR} \text { spectrum of } \mathbf{3} & \text { S18 }\end{array}$

$\begin{array}{ll}\text { Carbonic anhydrase inhibition } & \text { S19 }\end{array}$

$\begin{array}{ll}\text { References } & \text { S20 }\end{array}$ 
General methods: Commercial reagents were used as received. All reactions were carried out under magnetic stirring and monitored by TLC on $0.25 \mathrm{~mm}$ silica gel plates (Merck F254). Column chromatographies were carried out on Silica Gel $60(32-63 \mu \mathrm{m})$ or on silica gel (230-400 mesh, Merck). Yields refer to spectroscopically and analytically pure compounds unless otherwise stated. ${ }^{1} \mathrm{H}-\mathrm{NMR}$ spectra were recorded on a Varian Gemini $200 \mathrm{MHz}$, a Varian Mercury $400 \mathrm{MHz}$ or on a Varian INOVA $400 \mathrm{MHz}$ instruments at $25{ }^{\circ} \mathrm{C} .{ }^{13} \mathrm{C}-\mathrm{NMR}$ spectra were recorded on a Varian Gemini $200 \mathrm{MHz}$ or on a Varian Mercury $400 \mathrm{MHz}$ instruments. Chemical shifts are reported relative to $\mathrm{CDCl}_{3}\left({ }^{13} \mathrm{C}: \delta=77.0 \mathrm{ppm}\right)$. Integrals are in accordance with assignments, coupling constants are given in Hz. For detailed peak assignments 2D spectra were measured (COSY, HSQC, NOESY, and NOE as necessary). Small scale microwave assisted syntheses were carried out in a microwave apparatus for synthesis (CEM Discover) with an open reaction vessel and external surface sensor. IR spectra were recorded with a BX FTIR Perkin-Elmer system spectrophotometer. ESI-MS spectra were recorded with a Thermo Scientific ${ }^{\mathrm{TM}}$ LCQ fleet ion trap mass spectrometer. Elemental analyses were performed with a Thermo Finnigan FLASH EA 1112 CHN/S analyzer. Optical rotation measurements were performed on a JASCO DIP-370 polarimeter. 


\section{Synthesis of compound 8:}

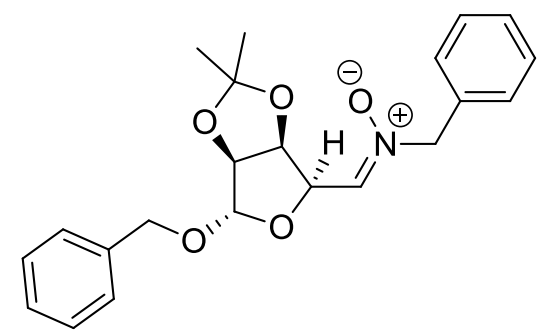

5
1) $\mathrm{Pd} / \mathrm{C}, \mathrm{H}_{2}$, $\mathrm{CH}_{3} \mathrm{COOH}, \mathrm{MeOH}$

r.t. , 2 d

2) Ambersep $900-\mathrm{OH}$ r.t , $40 \mathrm{~min}$<smiles>CC1(C)O[C@H]2CNC[C@@H](O)[C@H]2O1</smiles>

$8(100 \%)$

To a solution of nitrone 5 (915 mg, $2.39 \mathrm{mmol})$ in dry $\mathrm{MeOH}(150 \mathrm{~mL})$ acid acetic (2 equivalents) and $\mathrm{Pd} / \mathrm{C}$ $(458 \mathrm{mg})$ were added under nitrogen atmosphere. The mixture was stirred at room temperature under hydrogen atmosphere (balloon) for 2 days, until a control by ${ }^{1} \mathrm{HNMR}$ spectroscopy attested the presence of acetate salt of 8. The mixture was filtered through Celite ${ }^{\circledR}$ and the solvent was removed under reduced pressure. The corresponding free amine was obtained by dissolving the residue in $\mathrm{MeOH}$, then the strongly basic resin Ambersep $900-\mathrm{OH}$ was added, and the mixture was stirred for 40 minutes. The resin was removed by filtration to afford compound $\mathbf{8}(414 \mathrm{mg}, 2.39 \mathrm{mmol}, 100 \%$ yield) as a white solid.

8: ${ }^{1}$ HNMR (200 MHz, CD OD) $_{3} \delta=4.26-4.16$ (m, 1H, H-3), 3.91 (pt, J=6.1 Hz, 1H, H-4), 3.75-3.62 (m, 1H, H-5), 3.13 (dd, J=14.5, 2.5 Hz, 1H, Ha-2), 3.01-2.94 (m, 1H, Ha-6), 2.94-2.86 (m, 1H, Hb-2), 2.38 (dd, J= $13.1,9.2 \mathrm{~Hz}, 1 \mathrm{H}, \mathrm{Hb}-6), 1.50$ (s, 3H, Me), 1.35 (s, 3H, Me) ppm. 


\section{Synthesis of compound 4:}<smiles>CC1(C)OC2CNCC(O)C2O1</smiles>

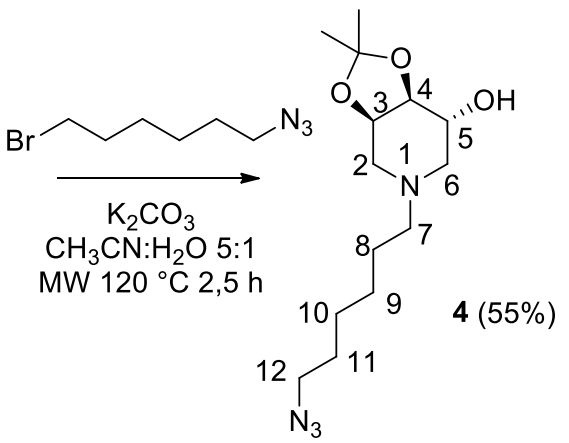

To a solution of compound $8(48 \mathrm{mg}, 0.28 \mathrm{mmol})$ in acetonitrile $(2 \mathrm{~mL})$ and milliQ water $(0.6 \mathrm{~mL})$, 1-azido6-bromohexane ( $86 \mathrm{mg}, 0.41 \mathrm{mmol})$ and potassium carbonate $(57 \mathrm{mg}, 0.41 \mathrm{mmol})$ were added. The mixture was stirred under microwave irradiation at $120^{\circ} \mathrm{C}$ for 2.5 hours, until a TLC control attested the disappearance of the starting material $\left(\mathrm{CH}_{2} \mathrm{Cl}_{2}\right.$ : $\mathrm{MeOH}$ 10:1). The mixture was filtered through Celite ${ }^{\circledR}$ and the solvent was removed under reduced pressure. The crude reaction was purified by silica gel flash column chromatography (eluent $\mathrm{CH}_{2} \mathrm{Cl}_{2}: \mathrm{MeOH}: \mathrm{NH}_{4} \mathrm{OH}(6 \%)$ 50:1:0.1, $\mathrm{R}_{\mathrm{f}}$ : 0.2) obtaining compound 4 (45 mg, $0.15 \mathrm{mmol}$, 55\% yield) as a yellow oil.

4: $[\alpha]_{D}^{22}:+17.8\left(\mathrm{CHCl}_{3}, c=0.6\right) . \mathbf{I R}\left(\mathrm{CHCl}_{3}\right): 814,1059,1142,1242,1377,1460,1666,2098,2862,2937$, 3001, $3481 \mathrm{~cm}^{-1}{ }^{1}{ }^{1}$ HNMR (400 MHz, $\left.\mathbf{C D C l}_{3}\right): \delta=4.27$ (pq, J=5.7 Hz, 1H, H-3), 4.01 (pt, J=4.3 Hz, 1H, H4), 3.93-3.91 (m, 1H, H-5), 3.24 (t, J=6.7 Hz, 2H, H-12), 2.70 (dd, J=11.8, $5.8 \mathrm{~Hz}, 1 \mathrm{H}, \mathrm{Ha}-2), 2.56$ (dd, J= 11.8, 3.0 Hz, 1H, Ha-6), 2.42-2.34 (m, 4H, Hb-2, Hb-6, H-7), 1.61-1.54 (m, 2H, H-11), 1.50-1.29 (m, 12H, H8, H-9, H-10, Me, Me) ppm. ${ }^{13} \mathbf{C N M R}\left(\mathbf{1 0 0} \mathbf{~ M H z}, \mathbf{C D C l}_{3}\right): \delta=109.4$ (s, 1C, O-C-O), 77.1 (d, 1C, C-4), 72.2 (d, 1C, C-3), 67.7 (d, 1C, C-5) 57.7 (t, 1C, C-7), 55.8 (t, 1C, C-2), 55.6 (t, 1C, C-6), 51.4 (t, 1C, C-12), 28.9 (t, 1C, C-11), 28.4 (t, 1C), 27.0 (t, 1C), 26.8 (t, 1C), 26.7 (q, Me), 26.5 (q, Me) ppm. $\mathrm{C}_{14} \mathrm{H}_{26} \mathrm{~N}_{4} \mathrm{O}_{3}$ : mass required $\mathrm{m} / \mathrm{z}$ 298.20; mass found-MS-ESI (m/z, \%): $299.11\left(100,[\mathrm{M}+\mathrm{H}]^{+}\right)$. Calcd. C, 56.35; H, 8.78; N, 18.78; found $\mathrm{C}, 56.58 ; \mathrm{H}, 8.53 ; \mathrm{N}, 18.92$. 

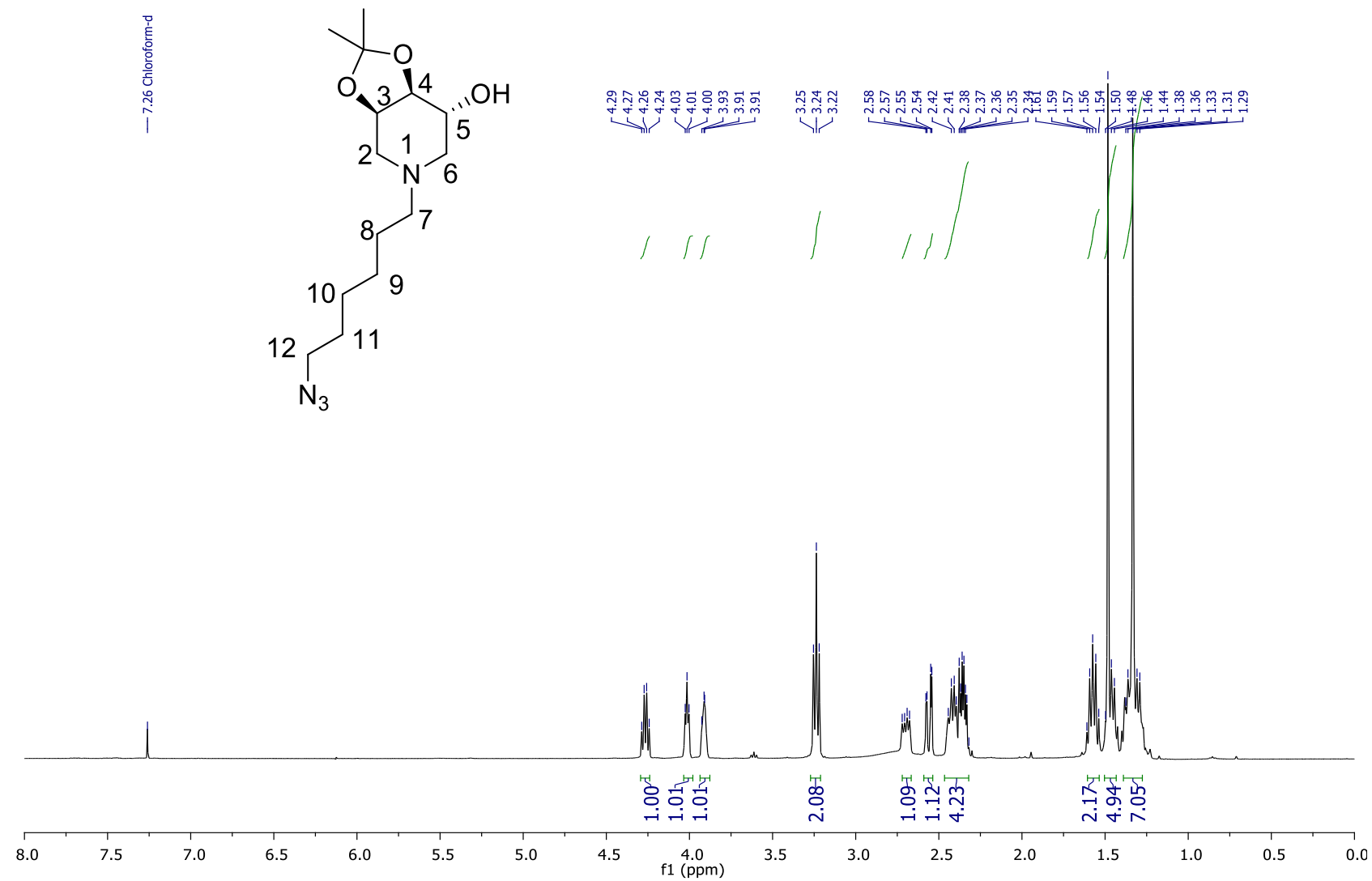

Figure S1. ${ }^{1} \mathrm{HNMR}$ spectrum of compound $4\left(400 \mathrm{MHz}, \mathrm{CDCl}_{3}\right)$.
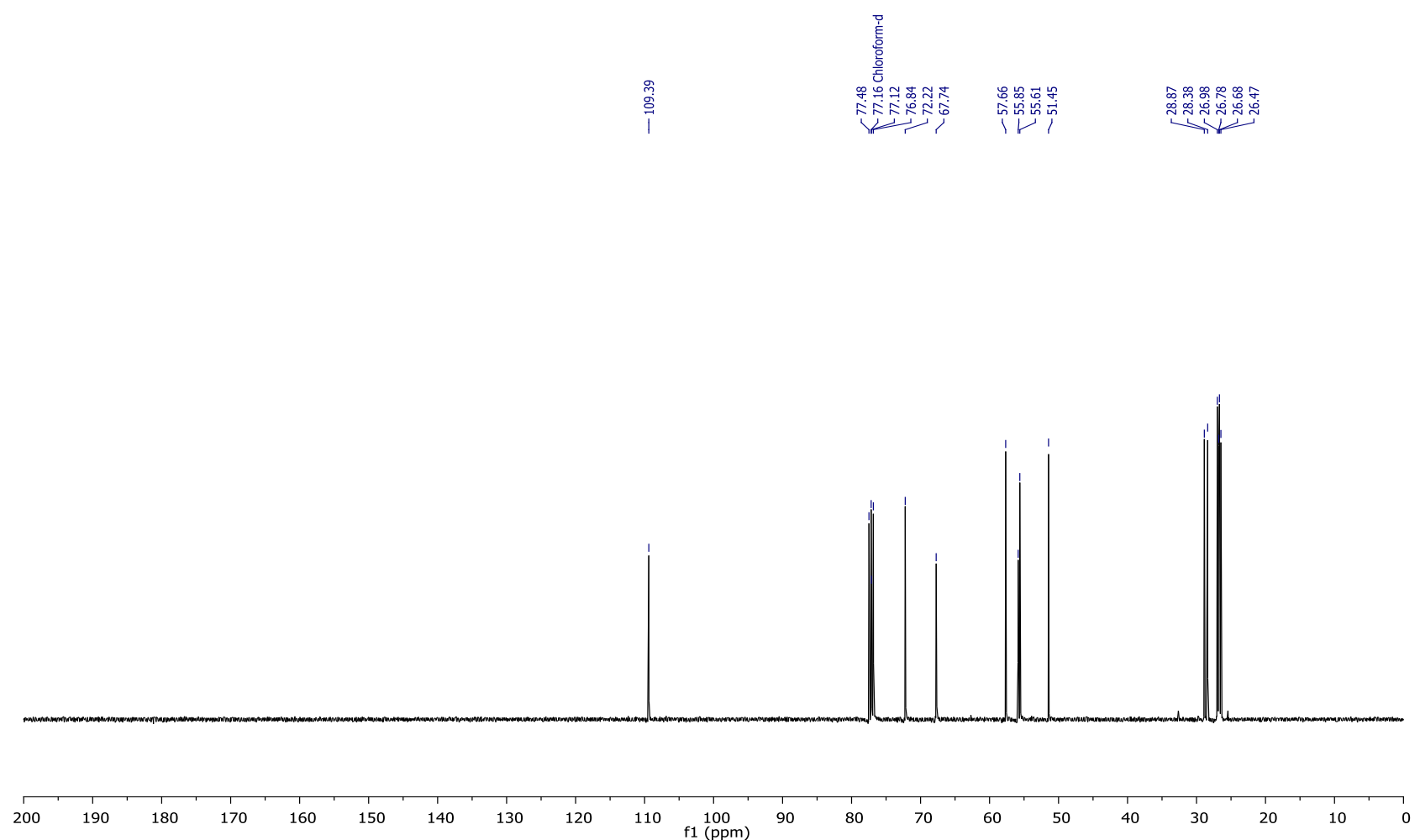

Figure S2. ${ }^{13} \mathrm{CNMR}$ spectrum of compound $4\left(100 \mathrm{MHz}, \mathrm{CDCl}_{3}\right)$. 


\section{Synthesis of compound 2:}
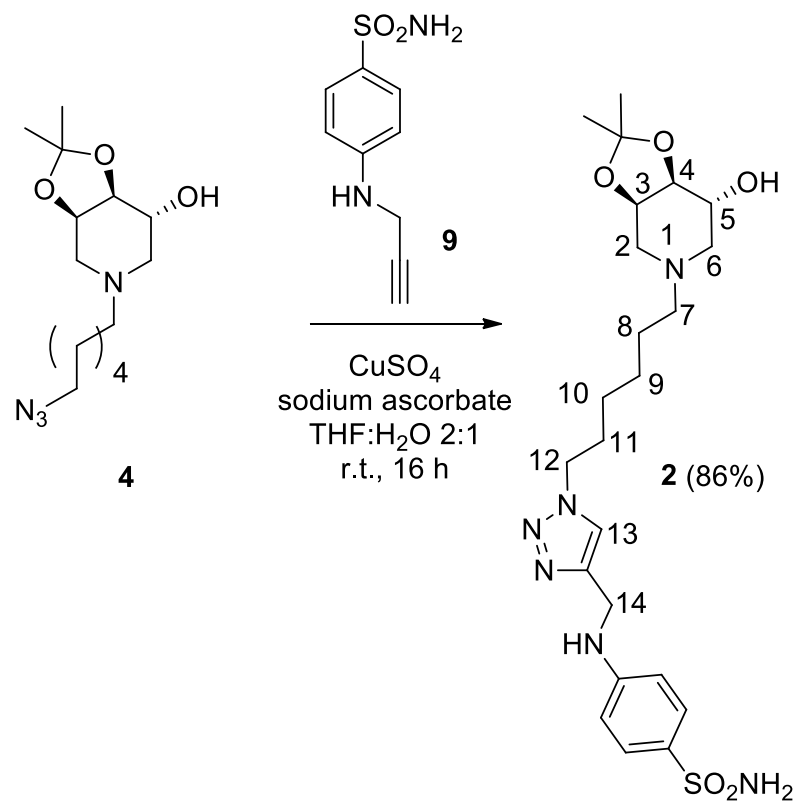

Sulfonamide 9 ( $33.1 \mathrm{mg}, 0.16 \mathrm{mmol}), \mathrm{CuSO}_{4}(6.85 \mathrm{mg}, 0.043 \mathrm{mmol})$ and sodium ascorbate $(17 \mathrm{mg}, 0.086$ mmol) was added to a solution of compound $4(42.7 \mathrm{mg}, 0.14 \mathrm{mmol})$ in THF $(2 \mathrm{~mL})$ and milliQ water (1 $\mathrm{mL}$ ). The reaction mixture was stirred at room temperature for 16 hours, until a TLC control attested the disappearance of the starting material (eluent $\mathrm{CH}_{2} \mathrm{Cl}_{2}: \mathrm{MeOH}$ : $\mathrm{NH}_{4} \mathrm{OH}(6 \%)$ 20:1:0.1). The mixture was filtered through Celite ${ }^{\circledR}$, the solvent was removed under reduced pressure and subsequently the crude mixture was treated with 'Quadrasil MP®' resin keeping the mixture under stirring at room temperature in the minimum amount of $\mathrm{MeOH}$ for 1 hour ( $1 \mathrm{~g}$ of resin for each mmol of copper). The crude was purified by silica gel flash column chromatography (eluent $\mathrm{CH}_{2} \mathrm{Cl}_{2}: \mathrm{MeOH}$ : $\mathrm{NH}_{4} \mathrm{OH}(6 \%)$ 10:1:0.1, $\mathrm{R}_{\mathrm{f}}: 0.3$ ) obtaining compound 2 (63 $\mathrm{mg}, 0.12 \mathrm{mmol}, 86 \%$ yield) as a colorless oil.

2: $[\alpha]_{D}^{22}:-17.2(\mathrm{MeOH}, c=1.08) . \mathbf{I R}(\mathrm{MeOH}): 868,1153,1331,1539,1601,2789,2990,3065,3152,3485$, $3607 \mathrm{~cm}^{-1}{ }^{1}$ HNMR (400 MHz, CD $\mathbf{3}$ OD): $\delta=7.86(\mathrm{~s}, 1 \mathrm{H}, \mathrm{H}-13), 7.62(\mathrm{~d}, \mathrm{~J}=8.7 \mathrm{~Hz}, 2 \mathrm{H}, A r), 6.70(\mathrm{~d}, \mathrm{~J}=8.7$ $\mathrm{Hz}, 2 \mathrm{H}, A r), 4.45$ (s, 2H, H-14), 4.35 (t, J=6.7 Hz, 2H, H-12), 4.27 (pq, J=4.3 Hz, 1H, H-3), 3.84-3.79 (m, 2H, H-4, H-5), 2.98 (d, J=13.0 Hz, 1H, Ha-2), 2.70 (dd, J= 12.4, $4.1 \mathrm{~Hz}, 1 \mathrm{H}, \mathrm{Ha}-6), 2.40$ (dd, J= 13.0, $4.0 \mathrm{~Hz}$, 1H, Hb-2), 2.36-2.31 (m, 2H, H-7), 1.98 (dd, J= 12.0, $8.8 \mathrm{~Hz}, 1 \mathrm{H}, \mathrm{Hb}-6), 1.90-1.83$ (m, 2H, H-11), 1.48-1.28 (m, 12H, H-8, H-9, H-10, Me, Me) ppm. ${ }^{13}$ CNMR (100 MHz, CD $\left.\mathbf{O O D}\right): \delta=152.7$ (s, 1C, Ar), 147.1 (s, 1C, Ar), 131.4 (s, 1C, C triazole), 128.9 (d, 2C, Ar), 124.0 (d, 1C, C-13), 112.7 (d, 2C, Ar), 110.2 (s, 1C, O-C-O), 80.2 (d, 1C, C-4), 74.5 (d, 1C, C-3), 70.5 (d, 1C, C-5), 58.9 (t, 1C, C-7), 57.6 (t, 1C, C-6), 54.9 (t, 1C, C-2), 51.2 (t, 1C, C-12), 39.4 (t, 1C, C-14), 31.1 (t, 1C, C-11), 28.5 (t, 1C), 27.8 (t, 1C), 27.2 (t, 1C), 27.2 (q, 1C, $M e), 26.6$ (q, $1 \mathrm{C}, M e)$ ppm. $\mathrm{C}_{23} \mathrm{H}_{35} \mathrm{~N}_{6} \mathrm{O}_{5} \mathrm{~S}$ : mass required m/z 508.25; mass found-MS-ESI (m/z, \%):509.31 $\left(100,[\mathrm{M}+\mathrm{H}]^{+}\right), 531.36\left(100,[\mathrm{M}+\mathrm{Na}]^{+}\right)$. Calcd. C, 54.31; H, 7.13; N, 16.52; found C, 54.63; H, 6.85; N, 16.84. 


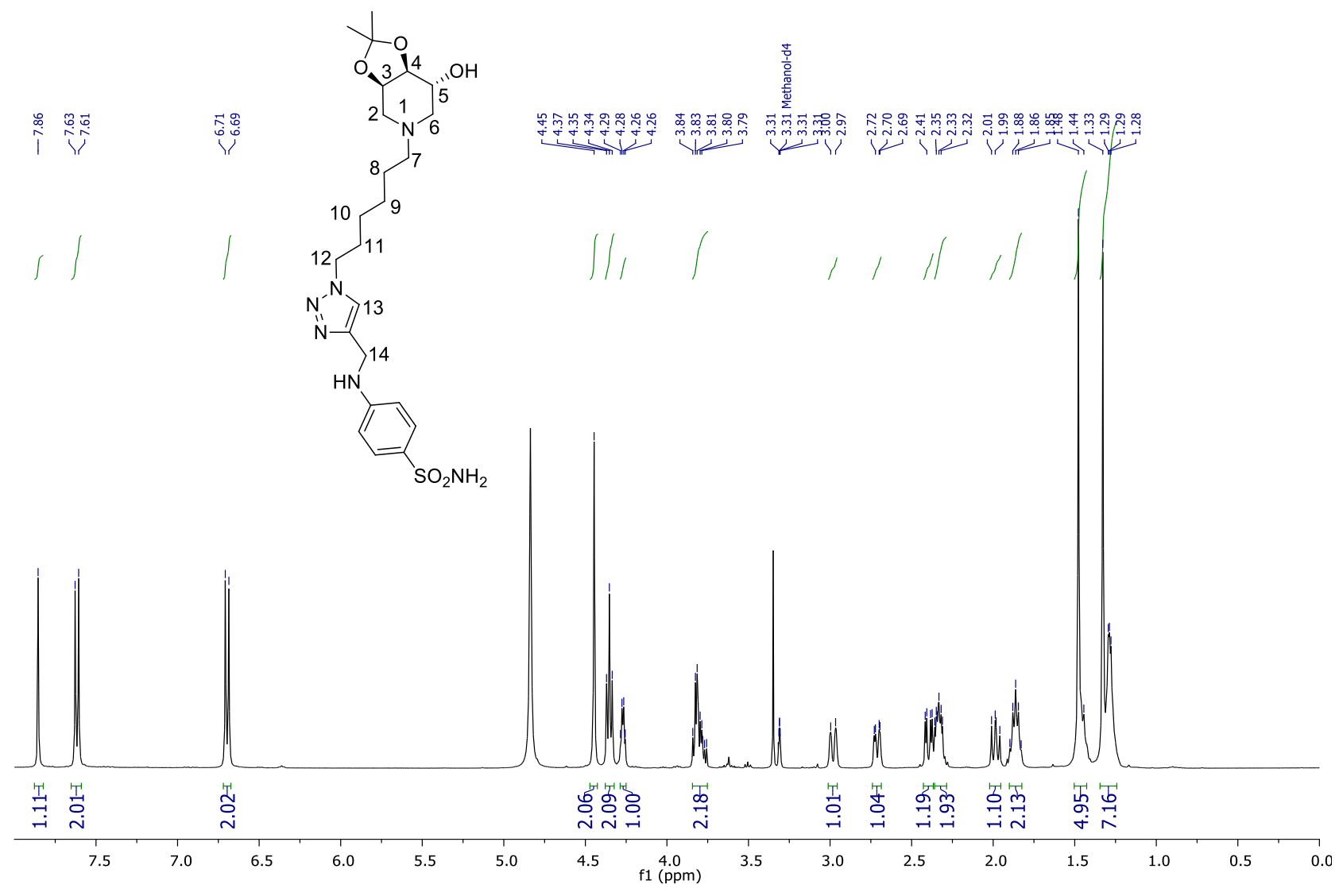

Figure S3. ${ }^{1} \mathrm{HNMR}$ spectrum of compound $2\left(400 \mathrm{MHz}, \mathrm{CD}_{3} \mathrm{OD}\right)$.
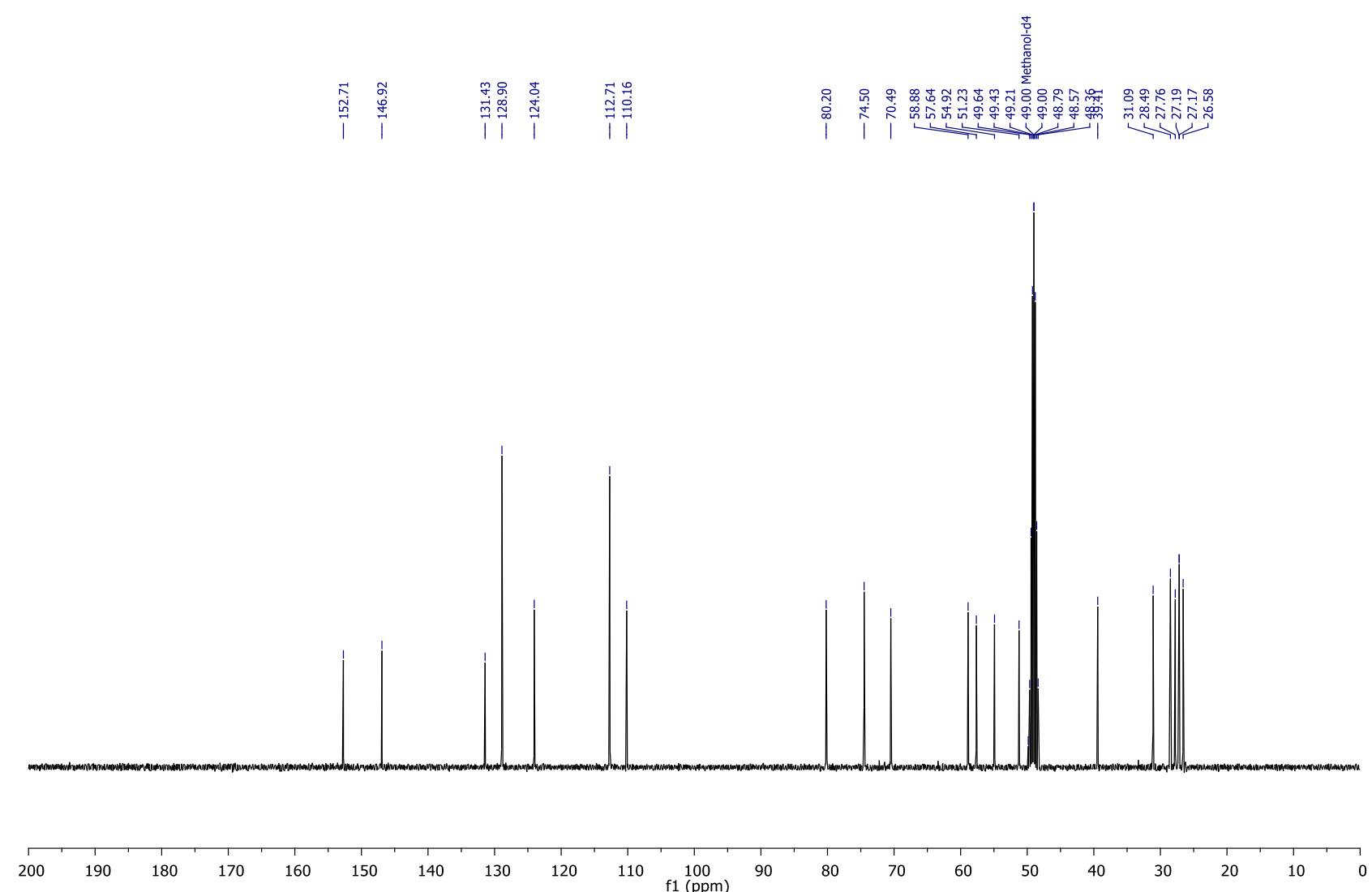

Figure S4. ${ }^{13} \mathrm{CNMR}$ spectrum of compound $2\left(100 \mathrm{MHz}, \mathrm{CD}_{3} \mathrm{OD}\right)$. 


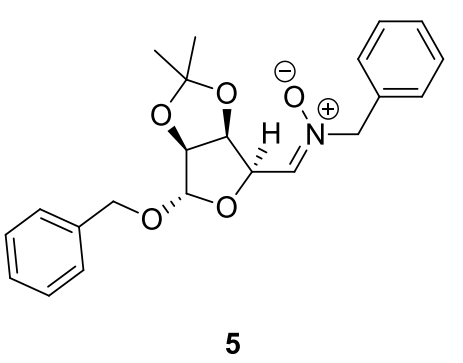

5
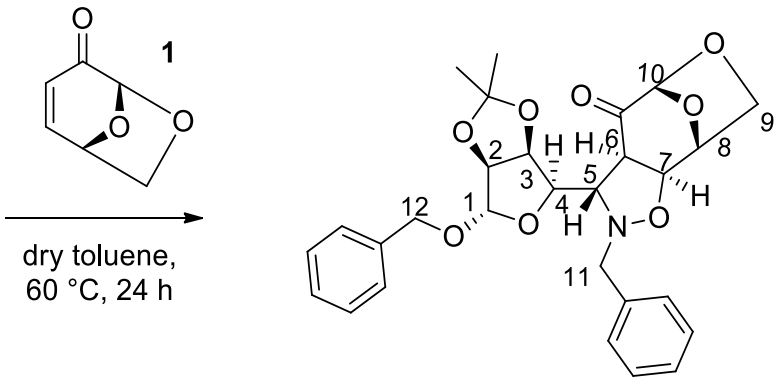

$10(78 \%)$

Levoglucosenone (1,135 mg, $1.07 \mathrm{mmol})$ was added under nitrogen atmosphere to a solution of compound $\mathbf{5}$ $(410 \mathrm{mg}, 1.07 \mathrm{mmol})$ in dry toluene $(1.5 \mathrm{~mL})$. The reaction mixture was stirred at $60{ }^{\circ} \mathrm{C}$ for 24 hours until a ${ }^{1}$ HNMR control attested the disappearance of the starting material. The solvent was evaporated at reduced pressure. The crude was purified by silica gel column chromatography with eluent of gradient polarity (Hexane: AcOEt 3:1 with $\mathrm{R}_{\mathrm{f}}$ : 0.25 and subsequently 7:3 with $\mathrm{R}_{\mathrm{f}}$ : 0.30 ) obtaining compound $\mathbf{1 0}$ (698 $\mathrm{mg}, 1.37$ mmol, $78 \%$ yield) as a white solid.

10: m. p.: $68-69^{\circ} \mathrm{C} .[\alpha]_{D}^{25}=-56.5\left(\mathrm{CHCl}_{3}, c=0.96\right)$. IR $\left(\mathrm{CHCl}_{3}\right): 3032,2988,2938,1744,1495,1456,1379$, 1227, 1211, 1161, 1115, 1082, 1020, $982 \mathrm{~cm}^{-1} .{ }^{1} \mathbf{H N M R}$ (400 MHz, $\left.\mathbf{C D C l}_{3}\right): \delta=7.43-7.24(\mathrm{~m}, 10 \mathrm{H}, A r), 5.29$ (s, 1H, H-10), 5.08 (s, 1H, H-1), 4.85-4.84 (m, 1H, H-4), 4.73-4.58 (m, 3H, H-2, H-8, H-9), 4.47-4.44 (m, 2H, H-7, H-9), 4.15-4.07 (m, 2H, H-11 or H-12), 3.99-3.91 (m, 3H, H-5, H-11 or H-12), 3.84 (dd, J= 6.3, $2.5 \mathrm{~Hz}$, 1H, H-3), 3.54 (dd, J=6.5, $3.5 \mathrm{~Hz}, 1 \mathrm{H}, \mathrm{H}-6), 1.46$ (s, 3H, Me), 1.28 (s, 3H, Me) ppm. ${ }^{13}$ CNMR (400 MHz, $\mathbf{C D C l}_{3}$ ): $\delta=197.6$ (s, 1C, CO), 137.3 (s, 1C, Ar), 137.2 (s, 1C, Ar), 129.4-127.7 (d, 10C, Ar), 112.7 (s, 1C, OC-O), 105.2 (d, 1C, C-1), 101.2 (d, 1C, C-10), 85.0 (d, 1C, C-8), 80.0 (d, 1C, C-2), 79.4 (d, 1C, C-3), 79.3 (d, 1C, C-7), 73.0 (d, 1C, C-4), 69.1 (t, 1C, C-9), 66.1 (t, 1C, C-11 o C-12), 65.6 (d, 1C, C-5), 63.3 (t, 1C, C-11 o C-12), 52.1 (d, 1C, C-6), 26.0 (q, 1C, Me), 24.7 (q, 1C, Me) ppm. $\mathrm{C}_{28} \mathrm{H}_{31} \mathrm{NO}_{8}$ : mass required m/z 509.20; mass found- MS-ESI $(\mathrm{m} / \mathrm{z}, \%): 532.10\left(100,[\mathrm{M}+\mathrm{Na}]^{+}\right)$. Calcd. C, 66.00; H, 6.13; N, 2.75; found C, 66.36; H, $5.90 ; \mathrm{N}, 2.88$. 


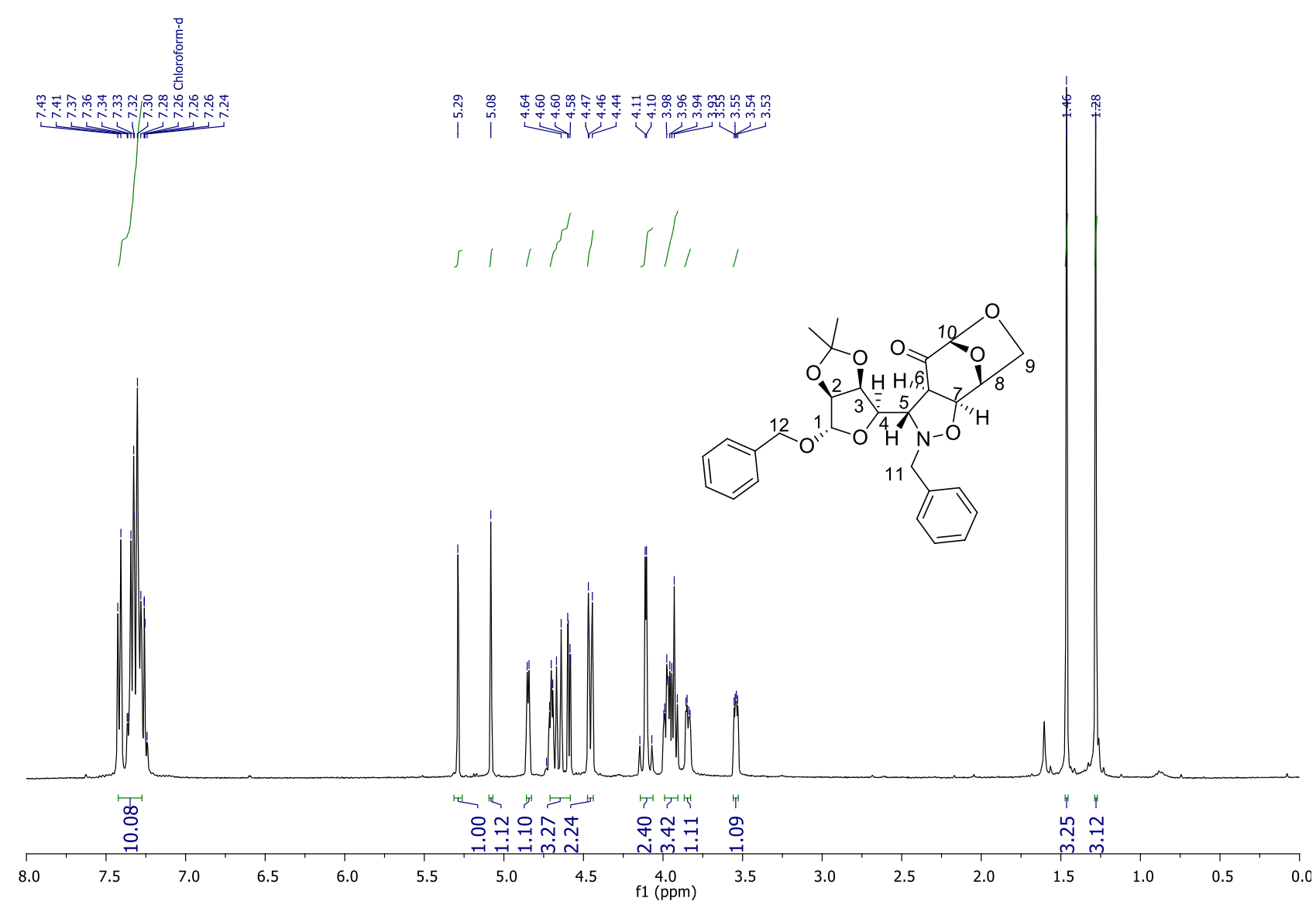

Figure S5. ${ }^{1} \mathrm{HNMR}$ spectrum of compound $10\left(400 \mathrm{MHz}, \mathrm{CDCl}_{3}\right)$.
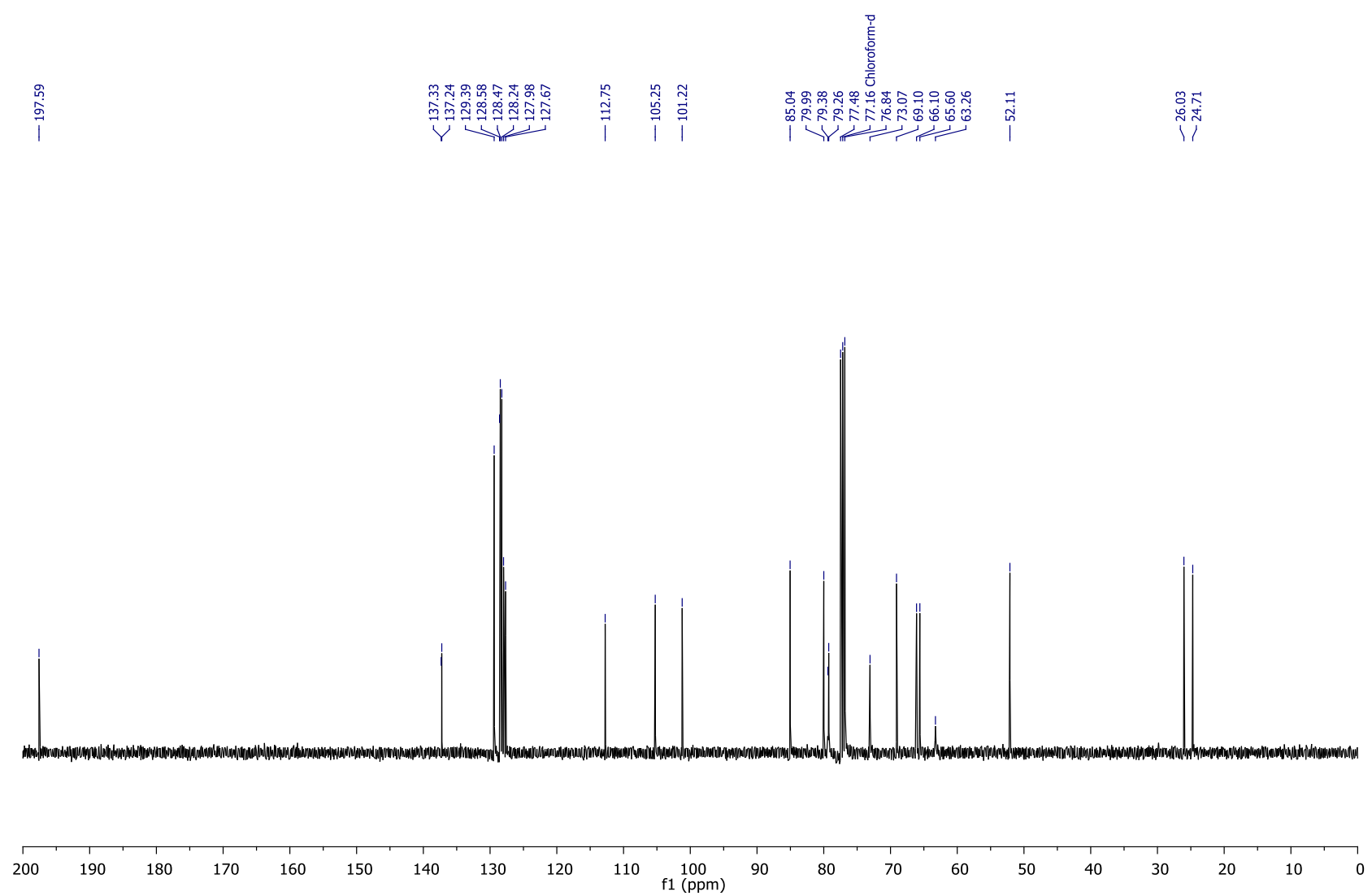

Figure S6. ${ }^{13} \mathrm{CNMR}$ spectrum of compound $10\left(100 \mathrm{MHz}, \mathrm{CDCl}_{3}\right)$. 


\section{Structural study on the 1,3-dipolar cycloadduct 10}

Based on 1D-NOESY spectra recorded in different deuterated solvents and logical considerations, the structure shown in Figure S13 was ascribed to compound 10. This stereoisomer derives from an endo-anti approach of dipole and dipolarophile, where endo indicates that nitrogen atom of the nitrone and the cycle of levoglucosenone are on the same side (the less sterically hindered for $Z$-configured nitrones) and anti means that nitrone approaches from the opposite side to the $-\mathrm{CH}_{2} \mathrm{O}$ bridge of levoglucosenone.

The correlations evidenced by the 1D-NOESY spectra allowed to rule out the stereoisomers derived from exo approaches. Instead, the found correlations between H-6 and H-3, H-6 and H-4, and H-3 and H-5 are in agreement with the structure 10 (Scheme 3). These interactions do not allow to definitely exclude formation of the endo-syn stereoisomer, which would however originate from a very crowded high energy conformation. Considering also the high steric hindrance which makes an endo-syn approach unlikely, we assigned the obtained cycloadduct the structure $\mathbf{1 0}$.

Figure S7. Structure of compound 10. The blue arrows indicate the observed correlations as visible in the 1DNOESY spectra

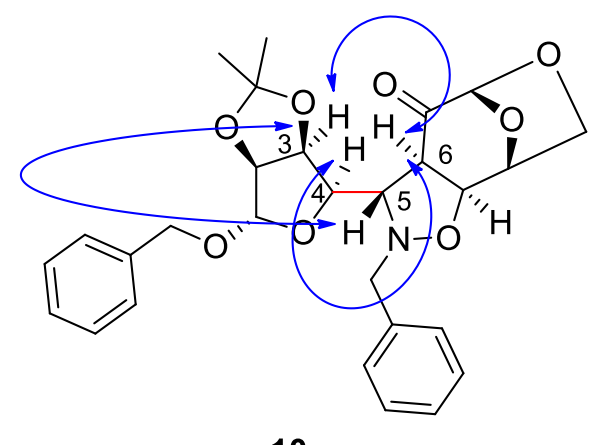

10

endo-anti approach

(- $\mathrm{CH}_{2} \mathrm{O}$ bridge) 

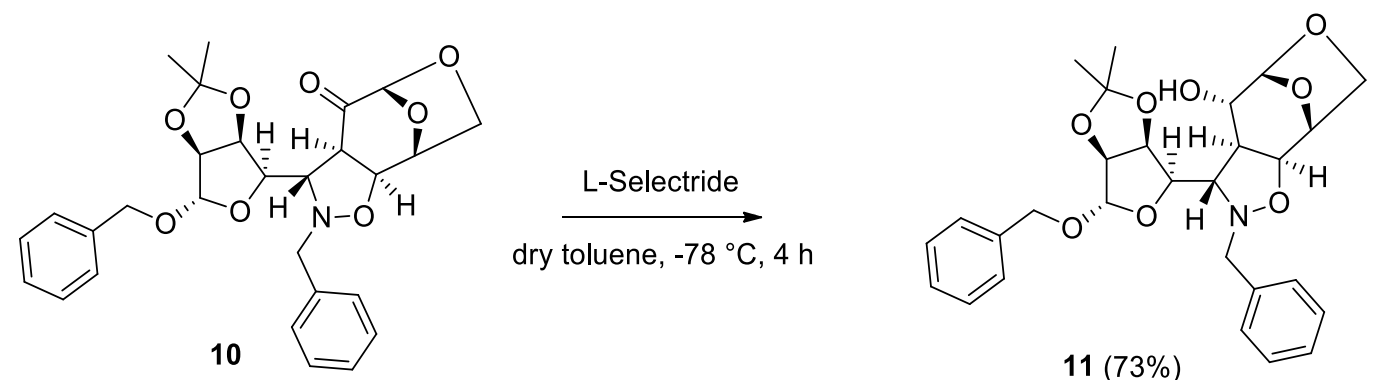

L-Selectride (1.52 mL, $1.36 \mathrm{mmol}$ ) was added under nitrogen atmosphere to a solution of compound $\mathbf{1 0}$ (631 $\mathrm{mg}, 1.24 \mathrm{mmol})$ in dry toluene $(60 \mathrm{~mL})$ at $-78^{\circ} \mathrm{C}$. The reaction was stirred at $-78^{\circ} \mathrm{C}$ for 4 hours, until a TLC control attested the disappearance of the starting material (eluent $\mathrm{CH}_{2} \mathrm{Cl}_{2}: \mathrm{MeOH}$ : $\mathrm{NEt}_{3}$ 90:1:0.1). A solution of $\mathrm{NH}_{4} \mathrm{Cl}$ was added to the reaction solution obtaining the formation of white salts. The mixture was left warming to room temperature and kept under stirring. A solution of $\mathrm{NaOH} 1 \mathrm{M}(30 \mathrm{~mL})$ and $\mathrm{H}_{2} \mathrm{O}_{2}$ at $30 \%(30$ $\mathrm{mL}$ ) was added and left stirring for 1 hour. The aqueous phase was extracted with $\mathrm{CH}_{2} \mathrm{Cl}_{2}(3 \times 60 \mathrm{~mL})$. The organic phase was washed with a solution of $\mathrm{NaHCO}_{3}(120 \mathrm{~mL})$ and brine $(2 \times 120 \mathrm{~mL})$, dried over $\mathrm{Na}_{2} \mathrm{SO}_{4}$ and concentrated under reduced pressure. The crude mixture was purified by silica gel column chromatography (eluent $\mathrm{CH}_{2} \mathrm{Cl}_{2}$ : $\mathrm{MeOH}$ : $\mathrm{NEt}_{3}$ 90: 1: 0.1, Rf: 0.08) obtaining compound 11 (460 mg, $0.90 \mathrm{mmol}, 73 \%$ yield) as a white solid.

11: m. p.: $149-150{ }^{\circ} \mathrm{C} .[\alpha]_{D}^{24}:-23.0\left(\mathrm{CHCl}_{3}, c=0.54\right)$. IR $\left(\mathrm{CHCl}_{3}\right): 3541,3007,1730,1377,1238$ $\mathrm{cm}^{-1} .{ }^{1}$ HNMR $\left(400 \mathrm{MHz}, \mathbf{C D C l}_{3}\right): \delta=7.47-7.26(\mathrm{~m}, 10 \mathrm{H}, \mathrm{Ar}), 5.50(\mathrm{~s}, 1 \mathrm{H}, \mathrm{H}-10), 5.14(\mathrm{~s}, 1 \mathrm{H}, \mathrm{H}-1), 4.78-$ 4.64 (m, 4H, H-4, H-8, H-12), 4.51-4.46 (m, 2H, H-2, Ha-9), 4.22 (dd= 9.8, 3.4 Hz, 1H, H-3), 4.14 (d, J= 12.0 $\mathrm{Hz}$ 1H, Hb-9), 3.85-3.80(m, 4H, H-5, H-7, H-11), 3.64-3.60 (m, 1H, H-13), 2.52-2.51 (m, 1H, H-6), 2.31-2.16 (bs, 1H, -OH), 1.49 (s, 3H, Me), 1.29 (s, 3H, Me) ppm. ${ }^{13} \mathbf{C N M R}\left(100 \mathbf{~ M H z}, \mathbf{C D C l}_{3}\right): \delta=138.3$ (s, $\left.1 \mathrm{C}, A r\right)$, 137.3 (s, 1C, Ar), 129.3-127.4 (d, 10C, Ar), 113.0 (s, 1C, O-C-O), 105.3 (d, 1C, C-1), 102.6 (d, 1C, C-10), 84.9 (d, 1C, C-2), 83.0 (d, 1C, C-3), 80.9 (d, 1C, C-4), 75.8 (d, 1C, C-7), 71.2 (t, 1C, C-8), 68.9 (d, 1C, C-12), 66.9 (d, 1C, C-5), 66.1 (t, 1C, C-13), 64.9 (d, 1C, C-11), 61.6 (t, 1C, C-9), 42.9 (d, 1C, C-6), 26.2 (q, 1C, Me), 25.0 (q, 1C, $M e$ ) ppm. $\mathrm{C}_{28} \mathrm{H}_{33} \mathrm{NO}_{8}$ : mass required m/z 511.22; mass found- MS-ESI (m/z, \%):1044.37 (100, $\left.[2 \mathrm{M}+\mathrm{Na}]^{+}\right), 534.21\left(80,[\mathrm{M}+\mathrm{Na}]^{+}\right)$. Calcd. C, 65.74; H, 6.50; N, 2.74; found $\mathrm{C}, 66.05 ; \mathrm{H}, 6.32 ; \mathrm{N}$, 2.93 . 


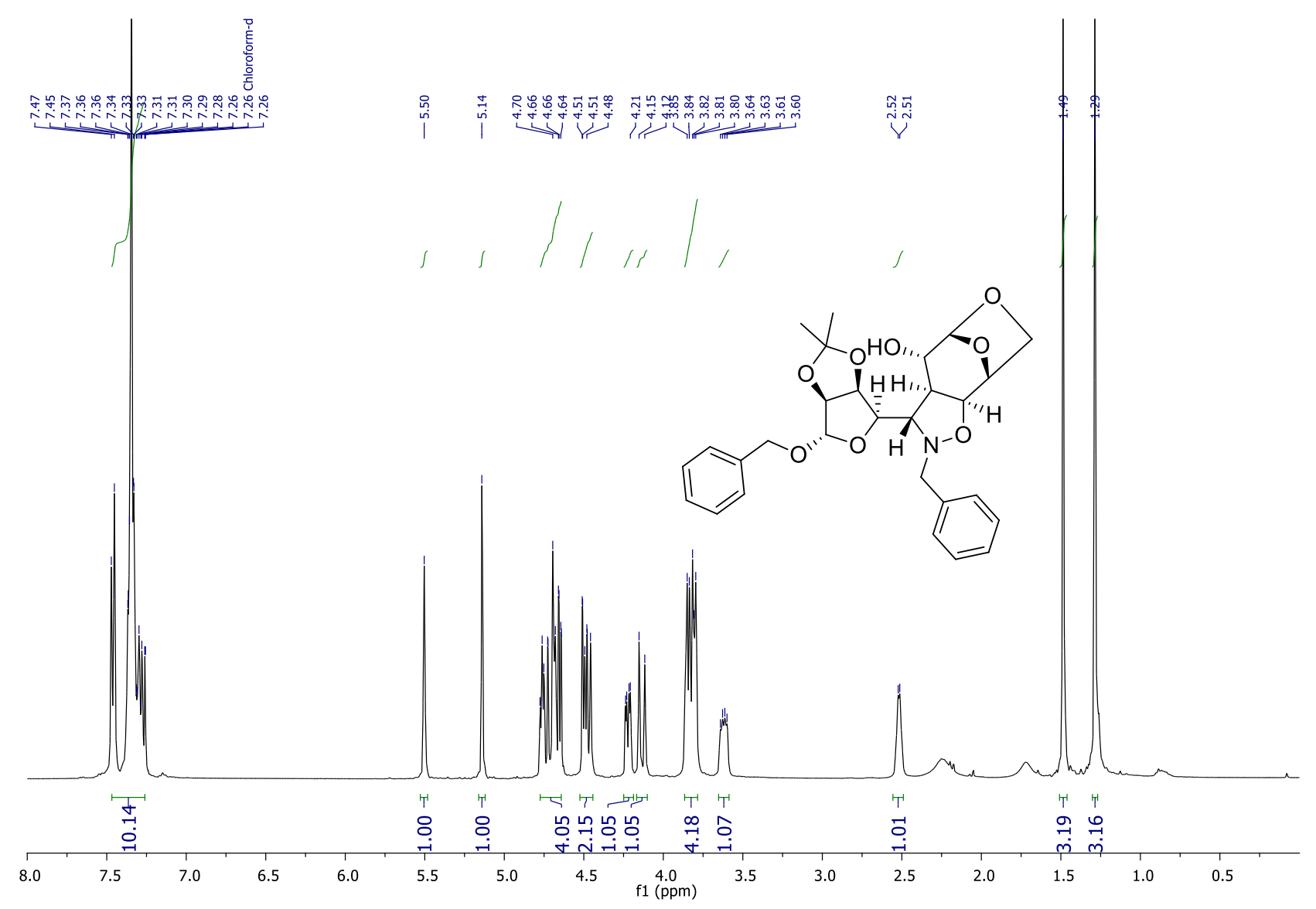

Figure S8. ${ }^{1} \mathrm{HNMR}$ spectrum of compound $11\left(400 \mathrm{MHz}, \mathrm{CDCl}_{3}\right)$.
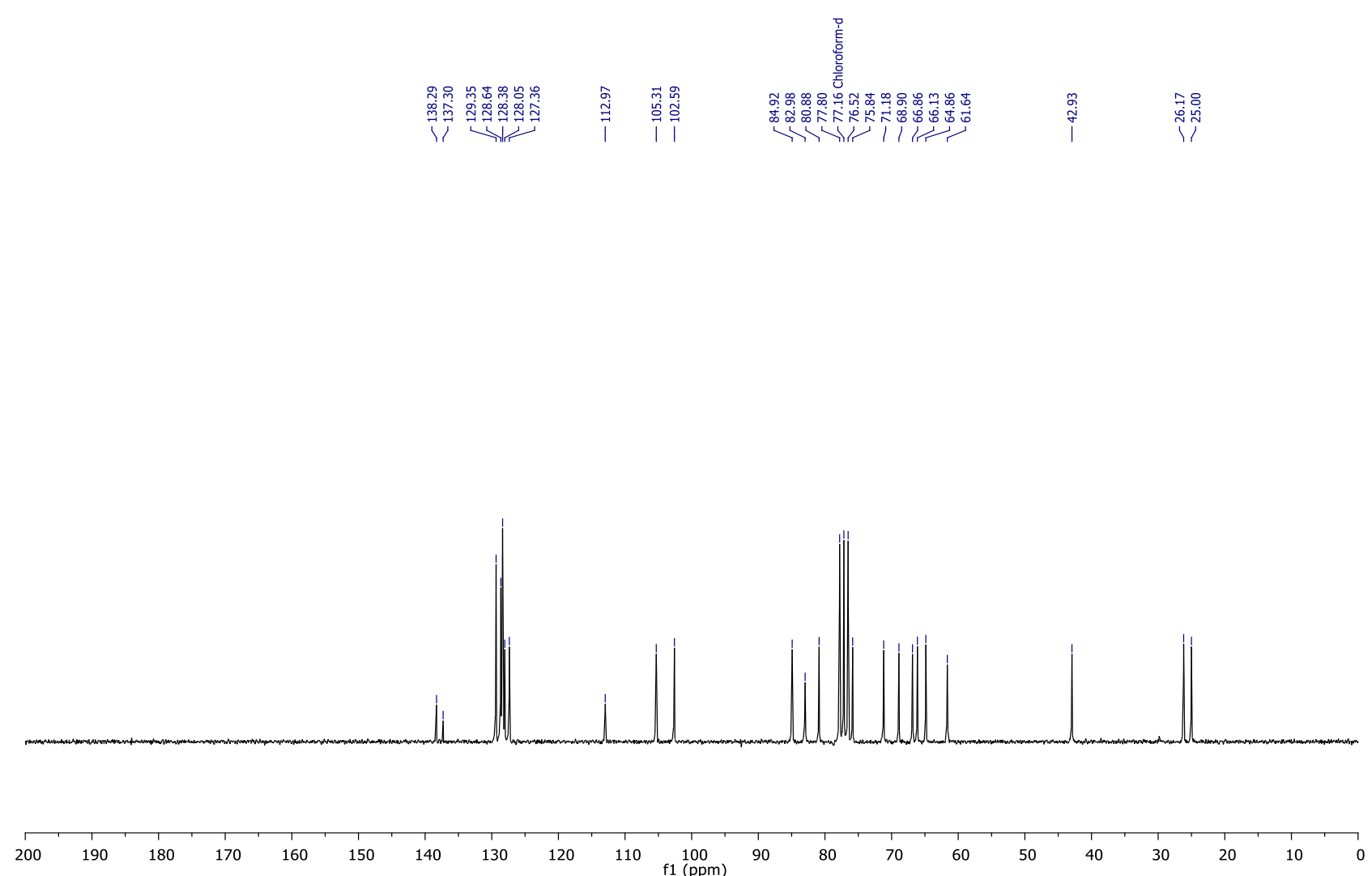

Figure S9. ${ }^{13} \mathrm{CNMR}$ spectrum of compound $11\left(100 \mathrm{MHz}, \mathrm{CDCl}_{3}\right)$. 

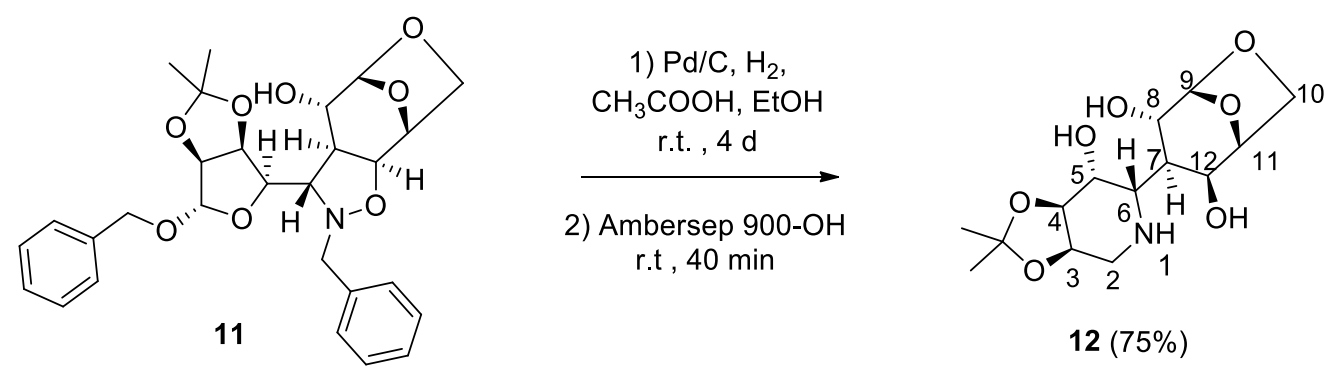

$12(75 \%)$

To a solution of 11 (230 mg, $0.45 \mathrm{mmol})$ in dry EtOH (15 mL), acid acetic (2 equivalents) and Pd/C (115 mg) were added under nitrogen atmosphere. The mixture was stirred at room temperature under hydrogen atmosphere (balloon) for 4 days, until a control by ${ }^{1} \mathrm{HNMR}$ spectroscopy attested the presence of acetate salt of compound 12. The mixture was filtered through Celite ${ }^{\circledR}$ and the solvent was removed under reduced pressure. The corresponding free amine was obtained by dissolving the residue in $\mathrm{EtOH}$, then adding the strongly basic resin Ambersep 900-OH and stirring the mixture for 40 minutes. The resin was removed by filtration and the crude product was purified by silica gel flash column chromatography (eluent $\mathrm{CH}_{2} \mathrm{Cl}_{2}$ : MeOH: $\mathrm{NH}_{4} \mathrm{OH}(6 \%)$ 30:1:0.1, $\mathrm{R}_{\mathrm{f}}$ : 0.05) obtaining compound 12 (103 mg, $0.32 \mathrm{mmol}, 75 \%$ yield) as a colorless oil.

12: $[\alpha]_{D}^{24}:-34.1(\mathrm{MeOH}, c=0.51)$. IR $(\mathrm{MeOH}): 3516,3046,2792,2361,1664 \mathrm{~cm}^{-1} .{ }^{\mathbf{1}} \mathbf{H N M R}(\mathbf{4 0 0} \mathbf{M H z}$, CD $_{3}$ OD): $\delta=5.24$ (d, J= 2.4 Hz, 1H, H-9), 4.51-4.49 (m, 1H, H-11), 4.23-4.16 (m, 2H, H-3, H-4), 4.01-4.00 (m, 1H, H-5), 3.77-3.75 (m, 2H, Ha-10, H-12), 3.68 (dd, J= 7.9, 5.4 Hz, 1H, Hb-10), 3.54-3.53 (m, 1H, H-8), 3.28-3.26 (m, 1H, H-6), 3.08 (dd, J=12.0, 4.6 Hz, 1H, Ha-2), 2.71 (dd, J= 12.0, $6.0 \mathrm{~Hz}, 1 \mathrm{H}, \mathrm{Hb}-2$ ), 1.99-1.94

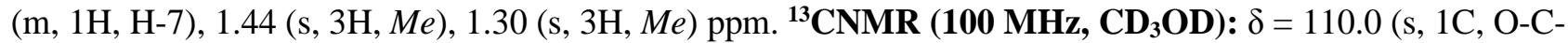
O), 103.4(d, 1C, C-9), 78.7 (d, 1C, C-11), 77.7 (d, 1C, C-3 o C-4), 72.1 (d, 1C, C-3 o C-4), 68.9 (d, 1C, C-8), 68.3 (d, 1C, C-12), 66.2 (t, 1C, C-10), 66.0 (d, 1C, C-5), 51.4 (d, 1C, C-6), 47.2 (t, 1C, C-2), 36.9 (d, 1C, C7), 28.1 (q, $1 \mathrm{C}, M e$ ), 26.0 (q, $1 \mathrm{C}, M e$ ) ppm. $\mathrm{C}_{14} \mathrm{H}_{23} \mathrm{NO}_{7}$ : mass required $\mathrm{m} / \mathrm{z} 317.15$; mass found-MS-ESI (m/z, \%): $318.21\left(100,[\mathrm{M}+\mathrm{H}]^{+}\right)$. Calcd. C, 52.99; H, 7.31; N, 4.41; found C, 53.31; H, 7.01; N, 4.60. 

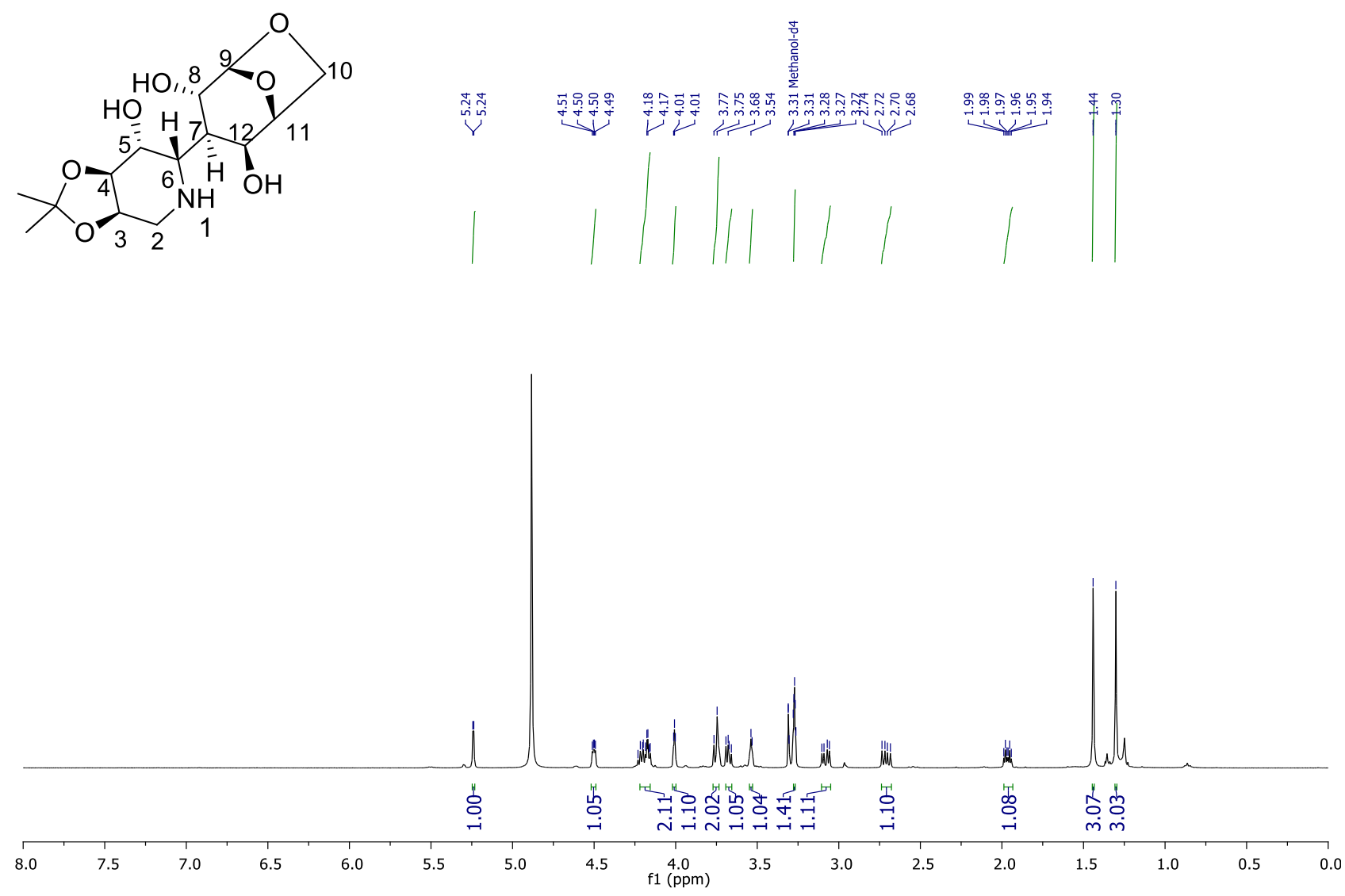

Figure S10. ${ }^{1} \mathrm{HNMR}$ spectrum of compound $12\left(400 \mathrm{MHz}, \mathrm{CD}_{3} \mathrm{OD}\right)$.

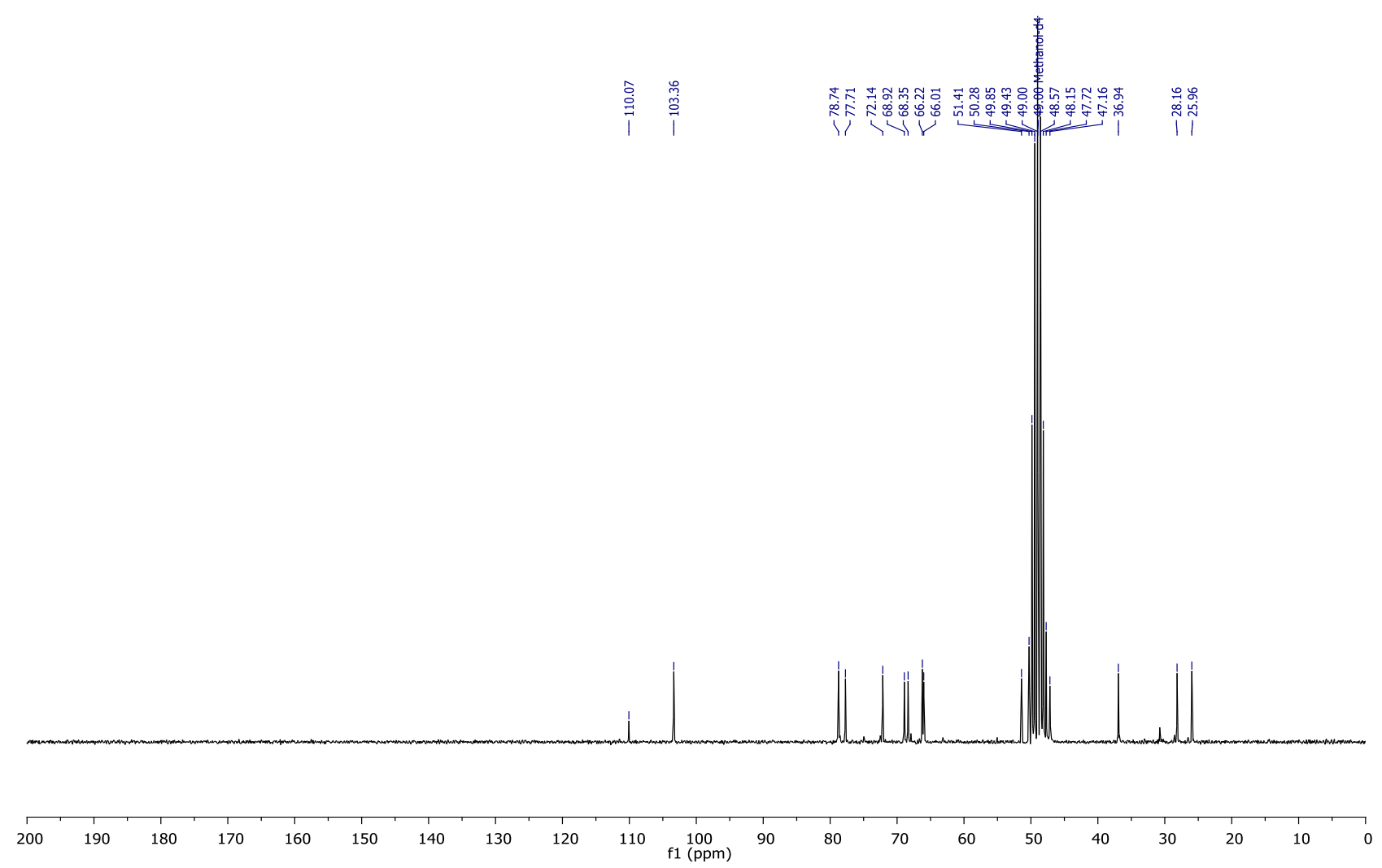

Figure S11. ${ }^{13} \mathrm{CNMR}$ spectrum of compound $12\left(50 \mathrm{MHz}, \mathrm{CD}_{3} \mathrm{OD}\right)$. 


\section{Synthesis of compound 3:}

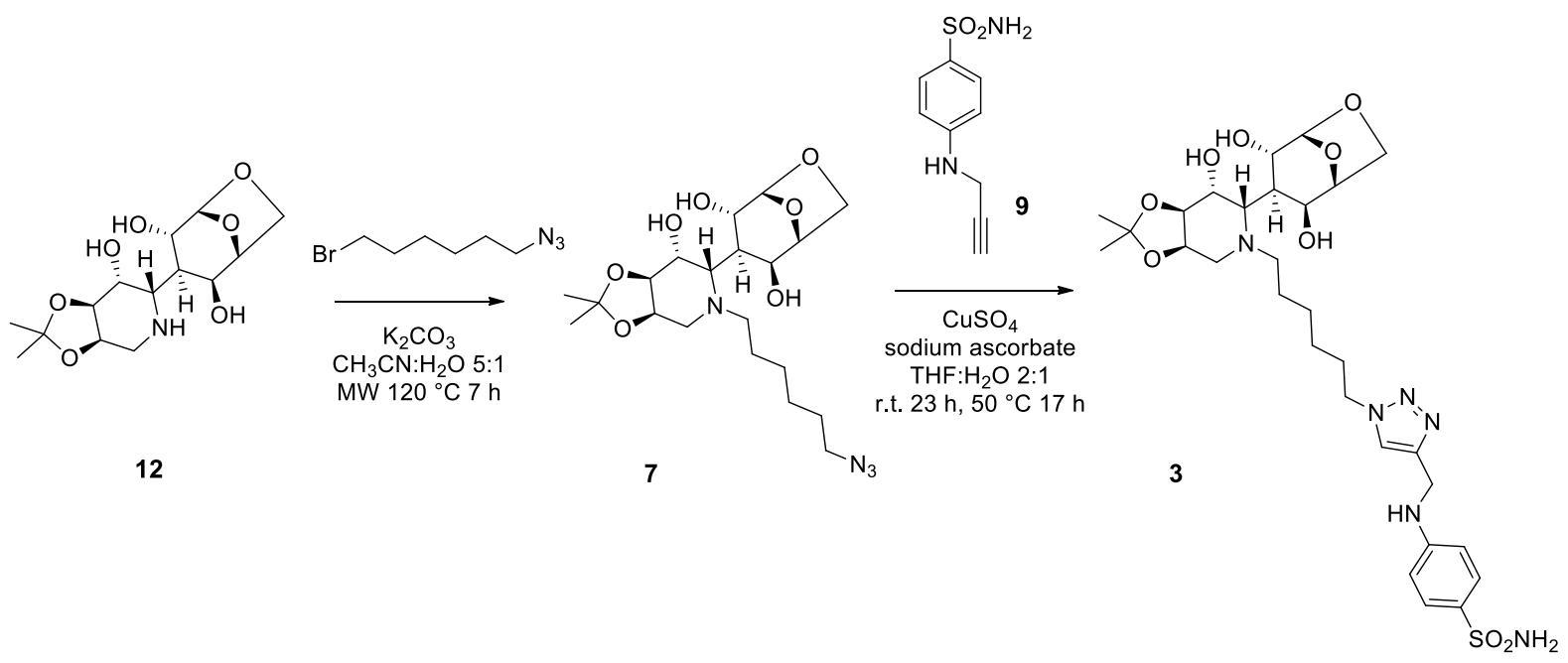

To a solution of compound $12(63 \mathrm{mg}, 0.20 \mathrm{mmol})$ in acetonitrile $(2 \mathrm{~mL})$ and milliQ water $(0.6 \mathrm{~mL})$ 1-azido6-bromohexane $(163 \mathrm{mg}, 0.80 \mathrm{mmol})$ and potassium carbonate $(109 \mathrm{mg}, 0.80 \mathrm{mmol})$ were added. The mixture was stirred at the microwave at $120{ }^{\circ} \mathrm{C}$ for 7 hours, until a TLC control attested the partial disappearance of the starting material $\left(\mathrm{CH}_{2} \mathrm{Cl}_{2}: \mathrm{MeOH}\right.$ 10:1). The mixture was filtered through Celite ${ }^{\circledR}$ and the solvent was removed under reduced pressure. The crude reaction was purified by silica gel flash column chromatography (eluent $\mathrm{CH}_{2} \mathrm{Cl}_{2}$ : $\mathrm{MeOH}: \mathrm{NH}_{4} \mathrm{OH}(6 \%)$ 20:1:0.1, $\mathrm{R}_{\mathrm{f}}$ : 0.3) obtaining compound 7 (19 mg, $0.043 \mathrm{mmol}$ ) containing some impurities that hampered complete characterization. Compound 7 was therefore directly employed in the next step. Sulfonamide $9(9.50 \mathrm{mg}, 0.045 \mathrm{mmol}), \mathrm{CuSO}_{4}(1.97 \mathrm{mg}, 0.012 \mathrm{mmol})$ and sodium ascorbate $(4.90 \mathrm{mg}, 0.025 \mathrm{mmol})$ were added to the solution of compound 7 (19 $\mathrm{mg}, 0.043 \mathrm{mmol})$ in THF (2 $\mathrm{mL})$ and milliQ water $(1 \mathrm{~mL})$. The reaction mixture was stirred at room temperature for 23 hours and subsequently at $50^{\circ} \mathrm{C}$ for 17 hours, until a TLC control attested the partial disappearance of the starting material (eluent $\mathrm{CH}_{2} \mathrm{Cl}_{2}: \mathrm{MeOH}$ 10:1). The mixture was filtered through Celite ${ }^{\circledR}$, the solvent was removed under reduced pressure and treated with 'Quadrasil MP®' resin keeping the mixture under stirring at room temperature in the minimum amount of $\mathrm{MeOH}$ for 1 hour ( $1 \mathrm{~g}$ of resin for each mmol of copper). The crude was purified by silica gel flash column chromatography (eluent $\mathrm{CH}_{2} \mathrm{Cl}_{2}: \mathrm{MeOH}: \mathrm{NH}_{4} \mathrm{OH}(6 \%)$ 10:1:0.1, $\mathrm{R}_{\mathrm{f}}$ : 0.14 ) obtaining compound $\mathbf{3}$ (14.2 $\mathrm{mg}, 0.022 \mathrm{mmol}, 12 \%$ yield) as a colorless oil.

7: $\mathrm{C}_{20} \mathrm{H}_{34} \mathrm{~N}_{4} \mathrm{O}_{7}$ : mass required m/z 442.24; mass found-MS-ESI (m/z, \%): $443.26\left(55,[\mathrm{M}+\mathrm{H}]^{+}\right), 465.25(50$, $\left.[\mathrm{M}+\mathrm{Na}]^{+}\right), 906.98\left(100,[2 \mathrm{M}+\mathrm{Na}]^{+}\right)$

3: $[\alpha]_{D}^{26}:-26.8(\mathrm{MeOH}, c=0.95) .{ }^{1}$ HNMR (400 MHz, CD 3 OD): $\delta=7.85$ (s, 1H, H-19), $7.62(\mathrm{~d}, \mathrm{~J}=9.1 \mathrm{~Hz}$, $2 \mathrm{H}, A r), 6.70(\mathrm{~d}, \mathrm{~J}=9.6 \mathrm{~Hz}, 2 \mathrm{H}, A r), 5.30(\mathrm{~d}, \mathrm{~J}=2.2 \mathrm{~Hz}, 1 \mathrm{H}, \mathrm{H}-9), 4.53-4.51(\mathrm{~m}, 1 \mathrm{H}, \mathrm{H}-11), 4.46(\mathrm{~s}, 1 \mathrm{H}, \mathrm{H}-$ 20), 4.37-4.34 (m, 1H, H-18), 4.32-4.28 (m, 1H, H-3), 4.20-4.11 (m, 2H, H-4, H-5), 3.81-3.63 (m, 4H, H-8, H-10, H-12), 3.35-3.32 (m, 1H, H-6), 3.11 (dd, J= 14.0, 4.2 Hz, 1H, Ha-2), 2.92-2.86 (m, 2H, H-13), 2.83-2.76 (m, 1H, Hb-2), 2.11-2.08 (m, 1H, H-7), 1.90-1.85 (m, 2H, H-17), 1.47-1.29 (m, 12H, H-14, H-15, H-16, Me, $\mathrm{Me}$ ) ppm. ${ }^{13} \mathrm{CNMR}\left(100 \mathrm{MHz}, \mathrm{CD}_{3} \mathrm{OD}\right): \delta=152.8$ (s, 1C, Ar), 147.0 (s, 1C, Ar), 131.5 (s, 1C, C triazole), 128.9 (d, 2C, Ar), 124.0 (d, 1C, C-19), 112.7 (d, 2C, Ar), 109.5 (s, 1C, O-C-O), 103.0 (d, 1C, C-9), 78.8 (d, 1C, C-11), 78.4 (d, 1C, C-4), 73.2 (d, 1C, C-3), 70.0 (d, 1C, C-8), 68.6 (d, 1C, C-12), 68.0 (d, 1C, C-5), 66.2 (t, 1C, C-10), 57.8 (d, 1C, C-6), 54.4 (t, 1C, C-13), 51.3 (t, 1C, C-18), 49.0 (t, 1C, C-2), 39.5 (t, 1C, C-20), 35.1 (d, 1C, C-7), 31.2 (t, 1C, C-17), 29.7 (t, 1C), 28.5 (t, 1C), 27.4 (t, 1C), 27.3 (q, 1C, Me), 25.9 (q, 1C, Me) ppm. $\mathrm{C}_{29} \mathrm{H}_{44} \mathrm{~N}_{6} \mathrm{O}_{9} \mathrm{~S}$ : mass required m/z 652.29; mass found- MS-ESI (m/z, \%): $653.38\left(100,[\mathrm{M}+\mathrm{H}]^{+}\right)$. Calcd. C, 53.36; H, 6.79; N, 12.87; found C, 53.67; H, 6.56; N, 12.99 . 

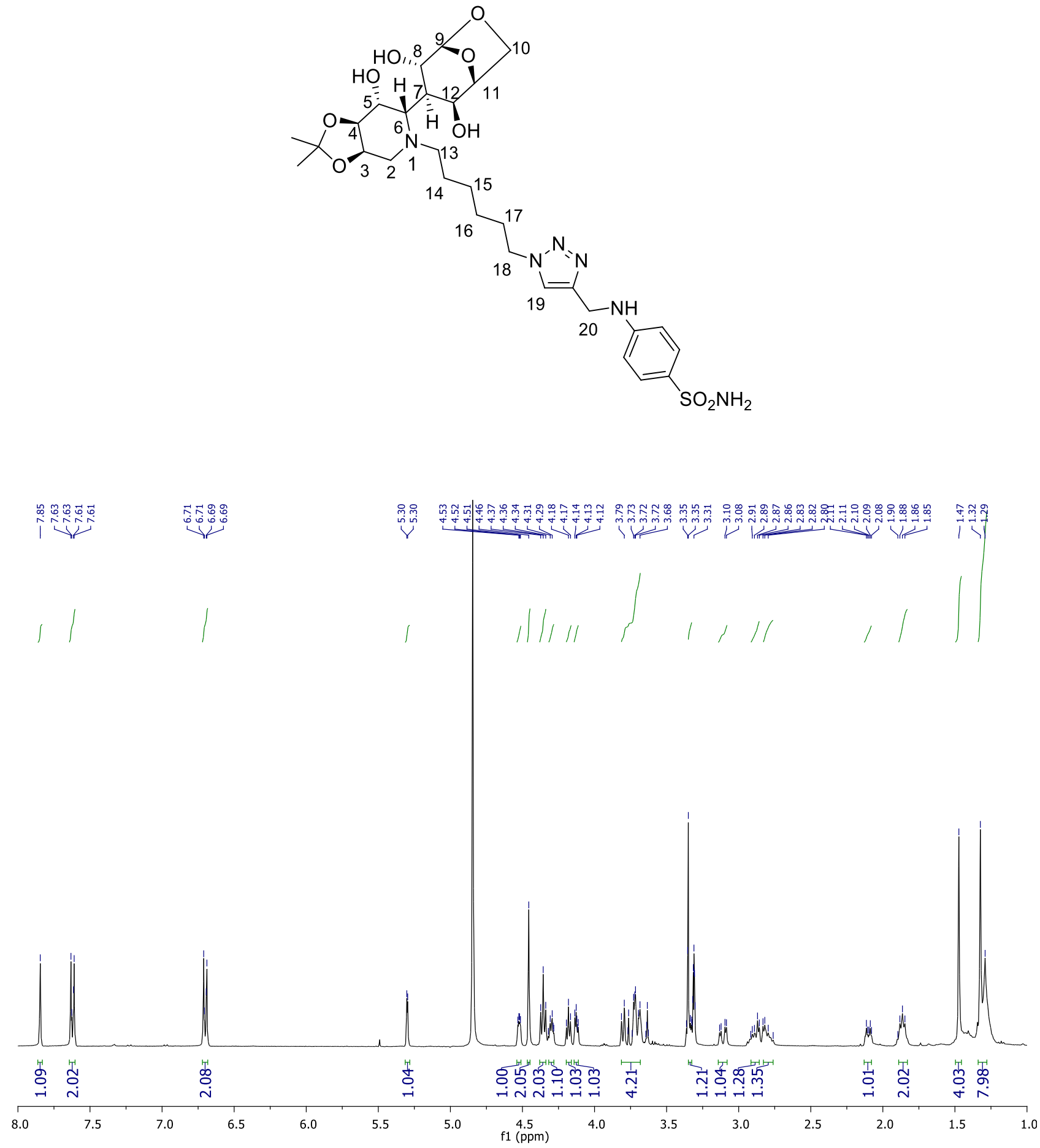

Figure S12. ${ }^{1} \mathrm{HNMR}$ spectrum of compound 3 (400 MHz, $\left.\mathrm{CD}_{3} \mathrm{OD}\right)$. 


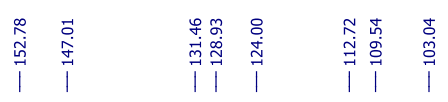

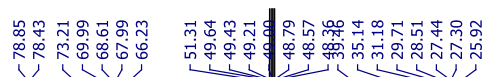

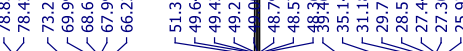

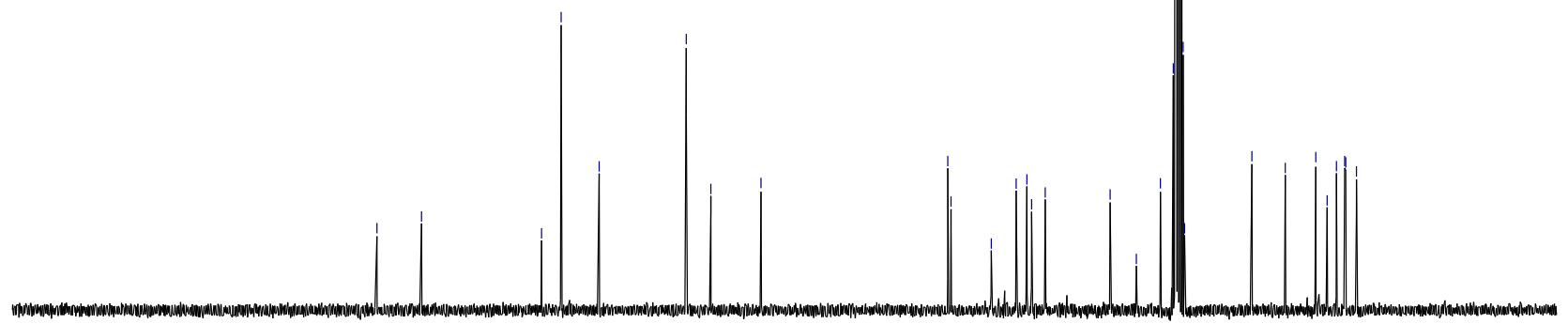

200

$190 \quad 180$

170

$150 \quad 140 \quad 130$

$\begin{array}{llc}120 & 110 & \begin{array}{c}100 \\ \mathrm{f} 1(\mathrm{ppm})\end{array}\end{array}$

Figure S13. ${ }^{13} \mathrm{CNMR}$ spectrum of compound $3\left(100 \mathrm{MHz}, \mathrm{CD}_{3} \mathrm{OD}\right)$. 


\section{Carbonic anhydrase inhibition}

An Applied Photophysics stopped-flow instrument has been used for assaying the $\mathrm{CA}$ catalyzed $\mathrm{CO}_{2}$ hydration activity. ${ }^{2}$ Phenol red (at a concentration of $0.2 \mathrm{mM}$ ) has been used as indicator, working at the absorbance maximum of $557 \mathrm{~nm}$, with $20 \mathrm{mMHepes}\left(\mathrm{pH} \mathrm{7.5)}\right.$ ) as buffer, and $20 \mathrm{mM} \mathrm{Na}_{2} \mathrm{SO}_{4}$ (for maintaining constant the ionic strength), following the initial rates of the $\mathrm{CA}$-catalyzed $\mathrm{CO}_{2}$ hydration reaction for a period of 10-100 s. The $\mathrm{CO}_{2}$ concentrations ranged from 1.7 to $17 \mathrm{mM}$ for the determination of the kinetic parameters and inhibition constants. For each inhibitor at least six traces of the initial 5-10\% of the reaction have been used for determining the initial velocity. The uncatalyzed rates were determined in the same manner and subtracted from the total observed rates. Stock solutions of inhibitor $(0.1 \mathrm{mM})$ were prepared in distilled-deionized water and dilutions up to $0.01 \mathrm{nM}$ were done thereafter with the assay buffer. Inhibitor and enzyme solutions were preincubated together for $15 \mathrm{~min}$ at room temperature prior to assay, in order to allow for the formation of the E-I complex. The inhibition constants were obtained by non-linear least-squares methods using PRISM 3 and the Cheng-Prusoff equation, as reported earlier, ${ }^{3-7}$ and represent the mean from at least three different determinations. All CA isofoms were recombinant ones obtained in-house as reported earlier. ${ }^{3-7}$ 


\section{References}

1. Matassini C., Mirabella S., Goti A., Cardona F. Double Reductive Amination and Selective Strecker Reaction of a D-Lyxaric Aldehyde: Synthesis of Diversely Functionalized 3,4,5Trihydroxypiperidines. Eur. J. Org. Chem. 2012, 3920-3924.

2. Khalifah R. G. The carbon dioxide hydration activity of carbonic anhydrase. I. Stop flow kinetic studies on the native human isoenzymes B and C. J. Biol. Chem. 1971, 246, 2561-2573.

3. Annunziato G., Angeli A., D'Alba F., Bruno A., Pieroni M., Vullo D., De Luca V., Capasso C., Supuran C. T. Costantino G. Discovery of New Potential Anti-Infective Compounds Based on Carbonic Anhydrase Inhibitors by Rational Target-Focused Repurposing Approaches. ChemMedChem 2016, 11, 1904-1914.

4. Angeli A., Carta F., Bartolucci G., Supuran C. T. Synthesis of novel acyl selenoureido benzensols as carbonic anhydrase I, II, VII and IX inhibitors, Bioorg Med Chem. 2017, 25, 3567-3573.

5. Angeli A., Peat T. S., Bartolucci G., Nocentini A., Supuran C. T., Carta F. Intramolecular oxidative deselenization of acylselenoureas: a facile synthesis of benzoxazole amides and carbonic anhydrase inhibitors. Org Biomol Chem. 2016, 14, 11353-11356.

6. Mishra C. B., Kumari S., Angeli A., Monti S. M., Buonanno M., Tiwari M., Supuran C. T. Discovery of Benzenesulfonamides with Potent Human Carbonic Anhydrase Inhibitory and Effective Anticonvulsant Action: Design, Synthesis, and Pharmacological Assessment. J Med Chem. 2017, 60, 2456-2469.

7. Angeli A., Abbas G., Del Prete S., Carta F., Capasso C. Supuran C. T. Acyl selenoureido benzensulfonamides show potent inhibitory activity against carbonic anhydrases from the pathogenic bacterium Vibrio cholerae. Bioorg Chem. 2017, 75, 170-172. 